Article

\title{
Evaluation of a Hydrogel-Based Diagnostic Approach for the Point-of-Care Based Detection of Neisseria gonorrhoeae
}

\author{
Sumudu R Perera ${ }^{1,2}$ (1) , Ali Taheri ${ }^{2}$ (D), Nurul H Khan ${ }^{2}$, Rajinder P Parti ${ }^{2}$, Stephanie Stefura ${ }^{3}$, \\ Pauline Skiba ${ }^{3}$, Jason P Acker ${ }^{3}$ (D), Irene Martin ${ }^{4}$, Anthony Kusalik ${ }^{5}$ (D) and \\ Jo-Anne R Dillon ${ }^{1,2, *}$ \\ 1 Department of Biochemistry Microbiology and Immunology, 2D01 Health Science Building, \\ 107 Wiggins Road, University of Saskatchewan, Saskatoon, SK S7N5E5, Canada; sumudu.perera@usask.ca \\ 2 Vaccine and Infectious Disease Organization-International Vaccine Centre, 120 Veterinary Road, Saskatoon, \\ SK S7N5E3, Canada; atahery@gmail.com (A.T.); khanmnh9@gmail.com (N.H.K.); rajparti@gmail.com (R.P.P.) \\ 3 Aquila Diagnostic Systems Inc., 4-034 National Institute for Nanotechnology, 11421 Saskatchewan Drive, \\ Edmonton, AB T6G2M9, Canada; sdc3@ualberta.ca (S.S.); pskiba@ualberta.ca (P.S.); \\ jason.acker@aquiladiagnostics.com (J.P.A) \\ 4 National Microbiology Laboratory, Streptococcus and STI Unit, Public Health Agency of Canada, \\ 1015 Arlington Street, Winnipeg, MB R3E 3R2, Canada; irene.martin@canada.ca \\ 5 Department of Computer Science, 176 Thorvaldson Building, 110 Science Place, University of Saskatchewan, \\ Saskatoon, SK S7N5C9, Canada; kusalik@cs.usask.ca \\ * Correspondence: j.dillon@usask.ca; Tel.: +1-306-966-1535
}

Received: 19 July 2018; Accepted: 2 August 2018; Published: 4 August 2018

\begin{abstract}
Eleven primer pairs were developed for the identification of Neisseria gonorrhoeae. The sensitivity and specificity of these primers were evaluated by Real Time (RT)-PCR melt curve analyses with DNA from $145 \mathrm{~N}$. gonorrhoeae isolates and 40 other Neisseria or non-Neisseria species. Three primer pairs were further evaluated in a hydrogel-based RT-PCR detection platform, using DNA extracted from $50 \mathrm{~N}$. gonorrhoeae cultures. We observed 100\% sensitivity and specificity in the hydrogel assay, confirming its potential as a point-of-care test (POCT) for N. gonorrhoeae diagnosis.
\end{abstract}

Keywords: Neisseria gonorrhoeae; molecular diagnosis; RT-PCR; hydrogel

\section{Introduction}

Neisseria gonorrhoeae, the second most prevalent bacterial sexually transmitted infection (STI) globally, causes 78 million new gonorrhea infections annually [1]. Rates of antimicrobial resistant (AMR) gonorrhea are rising worldwide [2]. Left untreated, gonococcal infections can cause severe and potentially life-threatening disease and reproductive complications, especially in women, including infertility or involuntary death of the fetus [2,3]. With no immunization available, the only way to eliminate infection is with effective antibiotic therapy $[4,5]$.

Early diagnosis of infection, preferably at the patient's first contact with the health care system, is vital for proper control of N. gonorrhoeae [6]. Traditional diagnosis of gonorrhea largely relied on microscopy and or culture of the organism from urogenital specimens. Highly sensitive and specific nucleic acid amplification tests (NAATs) have replaced these tests in resource rich settings [7-10]. In many resource poor settings, either the appropriate laboratory facilities are not available at the primary health care level, or the costs associated with diagnosis are unaffordable. In these instances, patients are treated empirically based on symptoms (i.e., syndromic management) [11,12]. Syndromic management often fails to identify asymptomatic infections and nay leave a large population of 
people at risk for ongoing transmission and severe complications [13,14]. Therefore, it is of the utmost importance to design rapid, easy to perform tests that can provide early diagnosis of N. gonorrhoeae even in asymptomatic patients.

An important factor contributing to the rising prevalence of gonorrhea is treatment delay, whereby a patient may wait for a positive diagnostic test result before treatment is initiated [15]. Sometimes, despite the availability of laboratory facilities, the delays in reporting results severely hinders timely treatment [6]. It has been shown by mathematical modeling that a rapid test with a sensitivity as low as $63 \%$ can drastically increase the number of patients treated, rather than waiting for a highly sensitive, yet slower test [16]. Likewise, although culture is considered the gold standard for a positive diagnosis, the number of infected individuals diagnosed by a rapid test and in turn successfully treated can outnumber the number of patients who return for treatment following extensive diagnostic procedures such as culturing and more sensitive NAATs [17]. Furthermore, viable organisms are required for culturing. Improper handling and transportation can reduce the viability of N. gonorrhoeae leading to false negative results. However, with NAATs, the viability of the organism is not a concern $[18,19]$.

The development of point-of-care tests (POCTs) for an STI such as gonorrhea is recognized as a vital approach to improve timely diagnosis [13,14,20-22]. Although POCTs are commercially available for the diagnosis of $N$. gonorrhoeae, many of these tests do not fit the ASSURED criteria important for STI diagnosis tests, such as affordability, sensitivity, specificity, user friendliness, robustness, and rapidness [13,21]. A reliable and rapid diagnostic test for $N$. gonorrhoeae would be a critical advancement in diagnostic capability.

The portable hydrogel-based RT-PCR method, developed by Aquila Diagnostic Systems Inc. Edmonton AB, Canada, is a rapid diagnostic platform utilizing Real Time Polymerase Chain Reaction (RT-PCR) melt curve analysis to amplify nucleic acids directly in clinical specimens and report the presence of specific genetic targets [23]. This system has successfully detected blood-borne infectious diseases such as malaria, BK virus, and herpes simplex virus [23-25]. We developed and evaluated eleven diagnostic primer pairs for the identification of $N$. gonorrhoeae. We then evaluated three of these primers with the hydrogel-based detection method to assess the potential of this method for further development as a POCT.

\section{Results}

\subsection{Evaluation of N. gonorrhoeae Diagnostic Primer Pairs}

From the eleven primer pairs tested (Table 1), nine primer pairs (3, 8-3, 8-4, 13, 16, 17-1, 17-2, 21-5, 31-2) amplified every $N$. gonorrhoeae isolate tested $(n=130)$ (Table 2). Primer pair 2 did not amplify one of the $130 \mathrm{~N}$. gonorrhoeae isolates. Primer pair 31-3 did not amplify 28 of the $130 \mathrm{~N}$. gonorrhoeae isolates. Primer pairs 2, 3, 8-4, 16, 17-1, 17-2, 21-5, 31-2, and 31-3 did not amplify any of the non-N. gonorrhoeae or non-Neisseria species. However, primer pair 8-3 amplified DNA from Neisseria flava, Neisseria lactamica, and Neisseria polysacchareae. Primer pair 13 amplified DNA from N. flava, Neisseria subflava, Neisseria mucosa, N. lactamica, Neisseria perflava, Neisseria flavescens, and N. polysacchareae (Table 2). The limit of detection of the primers was assessed by serially diluting $(10 \mathrm{ng} / \mu \mathrm{L}$ to $0.000001 \mathrm{ng} / \mu \mathrm{L})$ genomic DNA from $N$. gonorrhoeae strain WHO-M. After 30 cycles of $\mathrm{PCR}$, all the primers were able to detect gonococcal concentrations as low as $0.001 \mathrm{ng} / \mathrm{uL}$. 
Table 1. Primer sequences used in this study for detection of N. gonorrhoeae, their respective targets and copy numbers present in the N. gonorrhoeae genome.

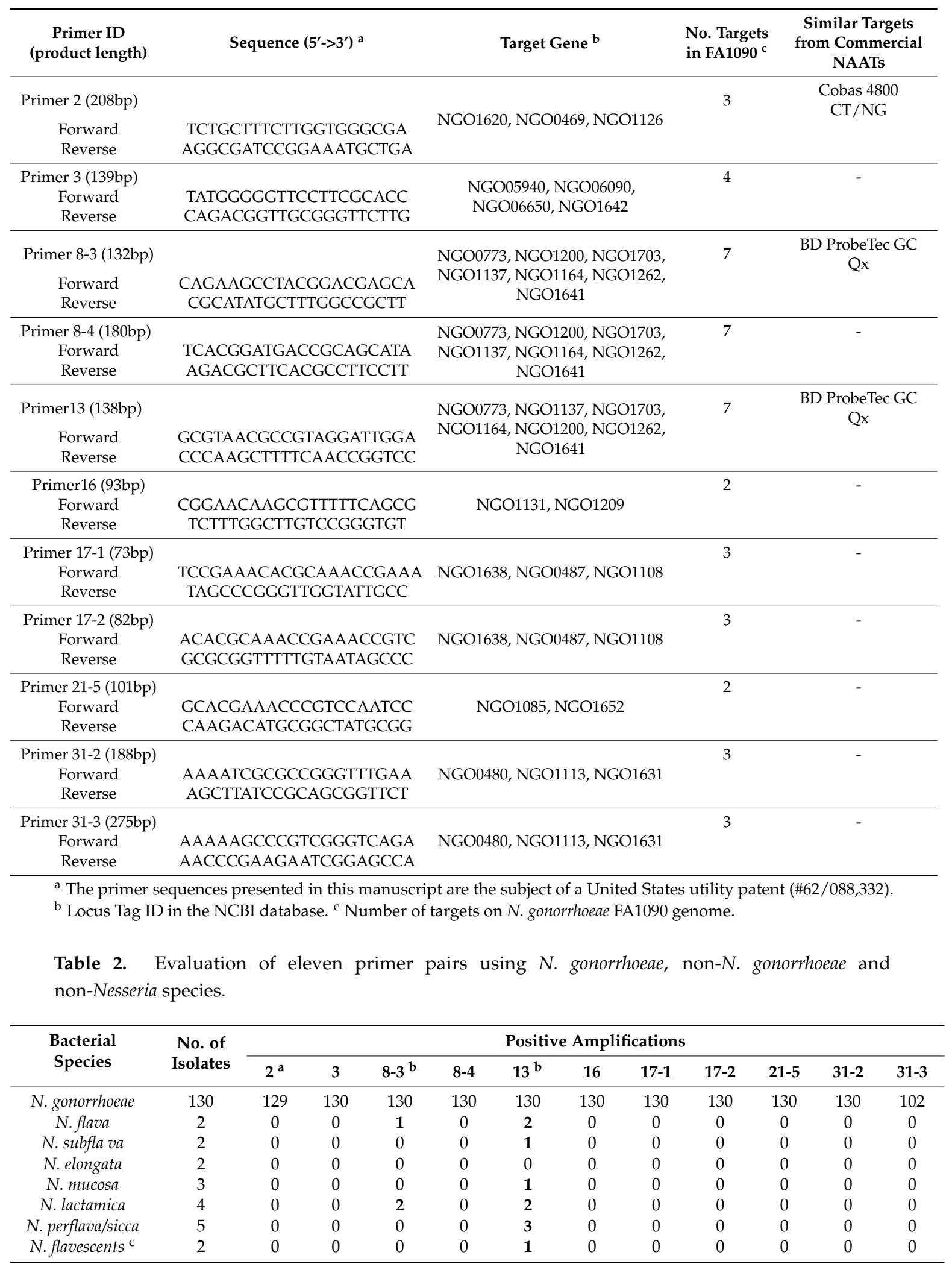


Table 2. Cont.

\begin{tabular}{|c|c|c|c|c|c|c|c|c|c|c|c|}
\hline N. polysacchareae & 4 & 0 & 0 & 1 & 0 & 2 & 0 & 0 & 0 & 0 & 0 \\
\hline $\begin{array}{l}\text { Other Neisseria } \\
\text { species }{ }^{\mathrm{d}}\end{array}$ & 6 & 0 & 0 & 0 & 0 & 0 & 0 & 0 & 0 & 0 & 0 \\
\hline $\begin{array}{l}\text { Non-Neisseria } \\
\text { species }\end{array}$ & 10 & 0 & 0 & 0 & 0 & 0 & 0 & 0 & 0 & 0 & 0 \\
\hline
\end{tabular}

\subsection{Optimization of the Hydrogel System and Comparison with RT-PCR Methods}

The ability of primers 3, 17-1, and 21-5 to identify genomic DNA from N. gonorrhoeae strains WHO F, WHO P, WHO G, WHO K, and WHO N in the hydrogel system was analyzed using RT-PCR (Table 3). To optimize the performance of the hydrogel system for N. gonorrhoeae, different parameters for hydrogel and RT-PCR were assessed. In testing for the most effective concentration of SYBR-Green, we determined that with $1 \times$ SYBR-Green (pre-mixed in the desiccated gel), primer pair 3 produced melt curve temperatures (Tm values) similar to previously established Tm values $\left(80.5^{\circ} \mathrm{C}\right.$ ) with control methods. However, with primer pairs 17-1 and 21-5, $2 \times$ SYBR-Green was required for established Tm values $\left(85.0^{\circ} \mathrm{C}\right)$. Therefore, $2 \times$ SYBR-Green was chosen for subsequent experiments. Further, with our primer pairs, we determined that optimal amplification occurred with 30 PCR cycles, which differs from the hydrogel manufacturer's recommendation of 40 cycles.

Table 3. The effect of SYBR-Green concentration on melt curve temperature (Tm values) of five $N$. gonorrhoeae strains, with primer pairs 3, 17-1, and 21-5.

\begin{tabular}{|c|c|c|c|c|c|c|}
\hline \multirow{3}{*}{ Strain } & \multicolumn{6}{|c|}{ Melt Curve Temperature $\left({ }^{\circ} \mathrm{C}\right)$} \\
\hline & \multicolumn{2}{|c|}{ Primer Pair $3^{a}$} & \multicolumn{2}{|c|}{ Primer Pair 17-1 a } & \multicolumn{2}{|c|}{ Primer Pair $21-5^{a}$} \\
\hline & $\begin{array}{c}1 \times \\
\text { SYBR-Green }\end{array}$ & $\begin{array}{c}2 \times \\
\text { SYBR-Green }\end{array}$ & $\begin{array}{c}1 \times \\
\text { SYBR-Green }\end{array}$ & $\begin{array}{c}2 \times \\
\text { SYBR-Green }\end{array}$ & $\begin{array}{c}1 \times \\
\text { SYBR-Green }\end{array}$ & $\begin{array}{c}2 \times \\
\text { SYBR-Green }\end{array}$ \\
\hline WHO-F & 80.49 & 81.52 & 83.90 & 84.64 & 84.05 & 84.84 \\
\hline WHO-G & 80.78 & 81.82 & 84.05 & 84.64 & 83.90 & 84.79 \\
\hline WHO-K & 80.49 & 81.97 & 84.05 & 84.49 & 84.20 & 84.79 \\
\hline WHO-N & 80.63 & 81.82 & 83.90 & 84.49 & 84.05 & 84.79 \\
\hline WHO-P & 80.93 & 81.97 & 83.90 & 84.64 & 84.05 & 84.79 \\
\hline
\end{tabular}

${ }^{\mathrm{a}}$ Expected Tm values for primer pair $3-80.5^{\circ} \mathrm{C}$; primer pair $17-1-85.0^{\circ} \mathrm{C}$; primer pair $21-5-85.0^{\circ} \mathrm{C}$.

The performance of the hydrogel method with increasing concentrations of DNA (50, 70, or $100 \mathrm{ng} / \mu \mathrm{L}$ ) was assessed using genomic DNA from 50 N. gonorrhoeae positive cultures (Table 4: Panel 2), WHO N. gonorrhoeae reference strains ( $n=5$; positive control) and non- $N$. gonorrhoeae strains $(n=4$; negative control). Based on the melt curve $(\mathrm{Tm})$ temperatures (primer pair $3,80.5{ }^{\circ} \mathrm{C}$; primer pairs 17-1 and 21-5, $85.0{ }^{\circ} \mathrm{C}$ ), primer pair 3 with $50 \mathrm{ng} / \mu \mathrm{L}$ DNA identified $44 \mathrm{~N}$. gonorrhoeae isolates. With $70 \mathrm{ng} / \mu \mathrm{L}$ DNA, primer pair 3 identified 46 isolates and with $100 \mathrm{ng} / \mu \mathrm{L}$ DNA identified all $50 \mathrm{~N}$. gonorrhoeae isolates (Table 5). Thus, primer pair $3 \mathrm{had} 88 \%, 92 \%$ and $100 \%$ sensitivity with 50,70 and $100 \mathrm{ng} / \mu \mathrm{L}$ DNA respectively. The specificity of primer pair 3 was $100 \%$ with all DNA concentrations tested. Primer pair 17-1, irrespective of the DNA concentration tested, identified all 50 N. gonorrhoeae isolates and had 100\% sensitivity and specificity. Primer pair 21-5 identified $47 \mathrm{~N}$. gonorrhoeae isolates with $50 \mathrm{ng} / \mu \mathrm{L}$ DNA and had a sensitivity of $94 \%$ and a specificity of $100 \%$. With $70 \mathrm{ng} / \mu \mathrm{L}$ and $100 \mathrm{ng} / \mu \mathrm{L}$ DNA, primer pair $21-5$ identify all 50 isolates and had $100 \%$ sensitivity and specificity. Primer pairs 3 and 17-1 in the control RT-PCR method identified all 50 N. gonorrhoeae isolates and had a 
sensitivity of $100 \%$. Primer pair $21-5$ identified 48 isolates with a sensitivity of $96 \%$. One non-Neisseria species (Escherichia coli) was incorrectly identified as N. gonorrhoeae positive by primer pair 3 in the RT-PCR control method, thereby giving a specificity of $67 \%$ (Table 5). With primer pairs $17-1$ and 21-5, all the negative control isolates (E. coli, Lactobacillus jensenii, Neisseria elongata, Neisseria subflava, and Salmonella enterica serovar Typhimurium) were correctly ascertained as N. gonorrhoeae negative, giving a specificity of $100 \%$.

Table 4. N. gonorrhoeae, non-N. gonorrhoeae, and non-Neisseria isolates used in this study.

\begin{tabular}{|c|c|c|c|c|}
\hline Isolate Selection & Organisms & Geographic Source & No & References \\
\hline \multirow{7}{*}{ Panel 1} & \multirow{5}{*}{ N. gonorrhoeae } & Saskatchewan & 86 & {$[26,27]$} \\
\hline & & USA & 13 & Dillon Culture Collection \\
\hline & & China & 8 & {$[28]$} \\
\hline & & $\mathrm{WHO}$ & 10 & [29] \\
\hline & & $\begin{array}{l}\text { South America and } \\
\text { the Caribbean }\end{array}$ & 28 & Dillon Culture Collection \\
\hline & Non-N. gonorrhoeae ${ }^{b}$ & Canada & 30 & $\mathrm{NML}^{\mathrm{a}}$ \\
\hline & Non-Neisseria species ${ }^{b}$ & Canada & 10 & NML \\
\hline \multirow{6}{*}{ Panel 2} & \multirow{4}{*}{ N. gonorrhoeae } & Saskatchewan & 35 & {$[26,27]$} \\
\hline & & China & 6 & {$[28]$} \\
\hline & & $\begin{array}{l}\text { South America and } \\
\text { the Caribbean }\end{array}$ & 9 & Dillon Culture Collection \\
\hline & & WHO & 5 & [29] \\
\hline & Non-N. gonorrhoeae ${ }^{\mathrm{c}}$ & Canada & 2 & NML \\
\hline & Non-Neisseria species ${ }^{c}$ & Canada & 3 & NML \\
\hline
\end{tabular}

${ }^{a}$ National Microbiology Laboratory. ${ }^{b}$ One isolate of: Enterococcus faecalis, Enterococcus faecium, Escherichia coli, Klebsiella oxytoca, Lactobacillus jensenii, Moxarella catarrhalis, Neisseria animaloris, Neisseria cinerea, Neisseria elongata, Neisseria flava, Neisseria lactamica, Neisseria menengitidis, Neisseria mucosa, Neisseria perflava, Neisseria polysacchareae, Neisseria sicca, Neisseria subflava, Neisseria wadsworthii, Neisseria weaverii, Pseudomonas aeruginosa, Salmonella enterica serovar Typhimurium, Staphylococcus aureus, and Staphylococcus epidermis. ${ }^{c}$ One isolate of: E. coli, L. jensenii, N. elongata, N. subflava, and S. enterica serovar Typhimurium.

Table 5. Evaluation of hydrogel and RT-PCR methods using varying concentrations of $N$. gonorrhoeae DNA $(n=50)^{\text {a }}$ and diagnostic primer pairs $3,17-1$, and 21-5.

\begin{tabular}{|c|c|c|c|c|c|c|}
\hline Primer Pair & Method & $\begin{array}{l}\text { DNA Conc. } \\
(\mathrm{ng} / \mu \mathrm{L})\end{array}$ & $\begin{array}{c}\text { No } N \text {. gonorrhoeae } \\
\text { Isolates Identified as } \\
\text { per Tm value }(n=50)^{b}\end{array}$ & $\begin{array}{c}\text { Positive } C t \\
\text { values }(n=50)\end{array}$ & $\begin{array}{c}\text { Sensitivity } \\
(\%)\end{array}$ & $\begin{array}{c}\text { Specificity } \\
(\%)\end{array}$ \\
\hline 3 & Hydrogel & 50 & 44 & 0 & 88 & 100 \\
\hline 3 & Hydrogel & 100 & 50 & 0 & 100 & 100 \\
\hline 3 & Hydrogel $+4 \times$ SYBR $^{d}$ & 100 & 50 & 50 & 100 & 100 \\
\hline 3 & RT-PCR control & 70 & 50 & 50 & 100 & $67^{c}$ \\
\hline $17-1$ & Hydrogel & 70 & 50 & 0 & 100 & 100 \\
\hline $17-1$ & Hydrogel & 100 & 50 & 0 & 100 & 100 \\
\hline $17-1$ & RT-PCR control & 70 & 50 & 50 & 100 & 100 \\
\hline $21-5$ & Hydrogel & 50 & 47 & 0 & 94 & 100 \\
\hline $21-5$ & Hydrogel & 70 & 50 & 0 & 100 & 100 \\
\hline $21-5$ & Hydrogel & 100 & 50 & 0 & 100 & 100 \\
\hline
\end{tabular}

${ }^{\text {a }}$ Controls-WHO N. gonorrhoeae reference strains ( $n=5$; positive control) and non-N. gonorrhoeae and non-Neisseria strains $\left(n=4\right.$; negative control). ${ }^{\mathrm{b}}$ Number of $N$. gonorrhoeae isolates identified as per the melt curve temperature $(\mathrm{Tm})$ and threshold cycle $(\mathrm{Ct})$ values. Isolates with negative $\mathrm{Ct}$ values had a positive melt curve temperature $(\mathrm{Tm})$. ${ }^{c}$ One Non- $N$. gonorrhoeae isolate identified as $N$. gonorrhoeae positive. d Hydrogel method pre-contained $2 \times$ SYBR-Green dye. For this assay, extra, fresh $2 \times$ SYBR-Green dye was added for a final concentration of $4 \times$ SYBR-Green dye.

With the hydrogel method and primer pair 3, 33 samples had positive threshold cycle $(\mathrm{Ct})$ values when using $70 \mathrm{ng} / \mu \mathrm{L}$ DNA. However, with $50 \mathrm{ng} / \mu \mathrm{L}$ and $100 \mathrm{ng} / \mu \mathrm{L}$ DNA, none of the samples had positive $C t$ values. Similarly, with primer pairs $17-1$ and $21-5$, all 50 samples had negative $C t$ 
values. In contrast, when using the control RT-PCR method and primer pair 3, all 50 samples had positive Ct values. Likewise, with primer pair 17-1, all 50 samples had positive Ct values. With primer pair 21-5, 49 samples had positive Ct values. To consider if the hydrogel system was interfering with the fluorescence reading, extra, fresh SYBR-Green (commercially made $2 \times$ SYBR-Green) was added to the reaction mixture of samples with the hydrogel method. These reaction mixtures pre-contained $2 \times$ SYBR-Green incorporated in to the desiccated gel. The addition of total $4 x$ and fresh SYBR-Green significantly improved the results from the hydrogel method and produced $\mathrm{Ct}$ values similar to that obtained with RT-PCR control method (Table 5).

\section{Discussion}

We developed and evaluated novel primers in a hydrogel platform as a potentially useful POCT for N. gonorrhoeae diagnosis. This system is rapid and requires minimal sample preparation. The hydrogel system introduces a state-of-the-art portable diagnostic approach to bringing a detection platform to clinicians and to remote locations, as this system contains desiccated primers, polymerases and other PCR components, thereby enabling the prompt delivery of results. Only the patient sample would need to be added to the system prior to PCR amplification. As such, this system does not require a cold chain (i.e., refrigeration) to preserve the PCR reagents, a major obstacle to delivering diagnostic tests to remote locations.

A recent review evaluated POCTs for N. gonorrhoeae [13]. The tests evaluated include lateral flow immunochromatographic test (ICT) formats, i.e., the Binax NOW Gonorrhoea Test (Inverness), the GC Check (PATH, Seattle, WA, USA) and, the ACON format tests (ACON Laboratories, San Diego, CA, USA); an optical immunoassay test (OIA), the BioStar (ThermoFisher/BioStar, Boulder, CO, USA); and a nucleic acid amplification test, the GeneXpert CT/NG Assay (Cepheid, Sunnyvale, CA, USA). The performance of the ICTs was variable with sensitivities ranging from $94 \%, 70 \%$, and $12.5 \%$ and specificities from 96\%, 97\%, and 99.8\% for Binax NOW, GC Check and ACON format tests, respectively. The OIA BioStar test had a sensitivity of $60 \%$ and a specificity of $89 \%$. The ICTs and the OIA had 5 or more steps and took 25 to 40 minutes to obtain results $[13,14]$. These tests generally fail to meet the high levels of sensitivity and specificity required for a POCT. The GeneXpert CT/NG Assay is the only commercial NAAT-based POCT for N. gonorrhoeae diagnosis and has high sensitivity (95.6-98\%) and specificity (99.9-100\%) which is dependent on the specimen type [13,30-33]. This assay requires 3 steps and takes 90 minutes to produce results [31]. The limiting factor about considering the GeneXpert as a POCT is affordability and portability of the equipment.

The currently available United States Food and Drug Administration approved commercial NAAT systems for N. gonorrhoeae identification primarily rely on a single target detection strategy [34]. These tests include the Abbott Real Time CT/NG assay which targets a 48bp sequence within the N. gonorrhoeae opa gene (Abbott Laboratories, Abbott Park, IL, USA), the Aptima COMBO 2 assay and the Aptima GC assay which target specific regions within N. gonorrhoeae 16S rRNA (Hologic/Gene-Probe Inc., San Diego, CA, USA), the BD ProbeTec ET CT/GC Amplified DNA assay and BD ProbeTec Qx GC Amplified DNA Assay which target the chromosomal pilin gene-inverting protein homologue (Becton Dickinson and Company, Sparks, MD, USA), the Cobas 4800 CT/NG which targets the DR-9 region (Roche Diagnostics, Indianapolis, IN, USA) and the GeneXpert CT/NG Assay (Cepheid, Sunnyvale, CA, USA) which uses two non-contiguous chromosomal targets (NG2 and NG4) of $N$. gonorrhoeae [7,30,31,34,35].

The hydrogel method we evaluated had $100 \%$ sensitivity and specificity using DNA from $N$. gonorrhoeae cultures. The system remains to be tested using clinical specimens of N. gonorrhoeae such as urines or self-collected vaginal or rectal swabs. One complication that arose with the hydrogel method was that, despite having a positive $N$. gonorrhoeae diagnosis by melt curve (Tm) analysis, most samples contained negative threshold cycle $(\mathrm{Ct})$ values. Therefore, we considered that the hydrogel system was interfering with the fluorescence reading, thereby giving $\mathrm{Ct}$ values lower than the threshold value (i.e., negative $\mathrm{Ct}$ values). Addition of extra, fresh $2 \times$ SYBR-Green to the hydrogel reaction mixture 
pre-containing $2 \times$ SYBR-Green, for a final concentration of $4 \times$ SYBR-Green resulted in favorable $\mathrm{C} t$ values. The hydrogel has been successfully used for the detection of other pathogens such as Herpes simplex virus from raw genital swabs, Plasmodium falciparum, BK virus, human platelet antigen $1\left(\mathrm{HPA}_{1}\right)$, and fibroblast growth factor receptor $2\left(\mathrm{FGFR}_{2}\right)$ from unprocessed blood samples [23-25]. Furthermore, the $<2$-hour time frame from specimen collection to results makes this test a potentially much simpler and user-friendly second molecular POCT.

The genomic targets of three of our primer pairs have partial homology with genomic targets used in two commercial assays. Primer pair 2 has partial homology with the genomic region used in the cobas $4800 \mathrm{CT} / \mathrm{NG}$ Test (i.e., DR-9 region) and primer pairs 8-3 and 13 have partial homology with the genomic targets used in the BD ProbeTec Amplified DNA Assays (i.e., chromosomal pilin gene-inverting protein homologue). In our assay, primer pair 2 did not amplify one N. gonorrhoeae isolate. Furthermore, cross-reactivity of primer pairs 8-3 and 13 with 3 and 7 other non-gonococcal Neisseria species respectively was observed. Cross-reactivity with Neisseria subflava and Neisseria lactamica was also reported for the BD ProbeTec GC $Q^{\mathrm{x}}$ Amplified DNA Assay [8].

\section{Materials and Methods}

\subsection{Bacterial Strains}

To determine the sensitivity and specificity of primer pairs developed by us for the identification of N. gonorrhoeae, DNA from $145 \mathrm{~N}$. gonorrhoeae isolates was obtained from the Dillon Culture Collection and represented isolates from diverse geographical areas [26-28] (Table 4: Panel 1). These isolates included the World Health Organization (WHO) N. gonorrhoeae reference isolates M, L, F, B, O, C, P, $\mathrm{K}, \mathrm{G}$, and N [29]. A random collection of 40 other Neisseria and non-Neisseria species were obtained from the National Microbiology Laboratory (NML), Winnipeg MB, Canada (Table 4: Panel 1).

For experiments evaluating the hydrogel platform, DNA from 50 cultured $N$. gonorrhoeae isolates was used (Table 4: Panel 2 is a sub-panel of Panel 1). WHO N. gonorrhoeae reference strains WHO-F, P, $\mathrm{G}, \mathrm{K}$ and N were used as positive controls. Five non-N. gonorrhoeae and non-Neisseria species (E. coli, L. jensenii, N. elongata, N. subflava, and S. enterica serovar Typhimurium) were used as negative controls.

\subsection{DNA Extraction}

DNA extraction was performed with a QIAamp DNA Mini Kit (\#51306 Qiagen Canada) according to manufacture's instructions. DNA was quantified using a NanoDrop 1000 Spectrophotometer (Thermo Fisher Scientific Inc., Wilmington DE, USA) and the final concentration was adjusted to 50, 70, or $100 \mathrm{ng} / \mu \mathrm{L}$ for evaluating the hydrogel method.

\subsection{Design of Diagnostic Primer Pairs}

Non-homologous sequence regions between N. gonorrhoeae FA1090 and N. meningitidis (MC58, FAM18 and Z2491) were extracted from the $N$. gonorrhoeae FA1090 genome. These sequences were then BLASTed against 25 in-house sequenced $N$. gonorrhoeae genomes and $15 \mathrm{~N}$. gonorrhoeae genomes available at the Broad Institute database. Sequences which were positive in this BLAST search (50 sequences) were then further aligned against the NCBI non-redundant (nr) database using the BLAST program. Regions which were only found in N. gonorrhoeae were filtered for further analysis. Targets for all primer pairs are present in multiple copies in the N. gonorrhoeae FA1090 genome and in turn increase the sensitivity of detection even at lower DNA concentrations. Based on these findings, eleven primer pairs were designed using Primer-BLAST [36] (Table 1). Potential cross-reactivity of the primer pairs was evaluated in silico using primer-BLAST software against the NCBI nr database. Primer pairs were tested in vitro for their sensitivity and specificity with N. gonorrhoeae, non-N. gonorrhoeae and non-Neisseria species. 


\subsection{Limit of Detection of Primers}

RT-PCR reactions contained $5 \mu \mathrm{L}$ of $2 \times$ SYBR-Green master mix (Cat \# 4472912, Life Technologies Inc.), $0.25 \mu \mathrm{L}$ of each primer $(10 \mu \mathrm{M}), 1 \mu \mathrm{L}$ of DNA $(50 \mathrm{ng} / \mu \mathrm{L})$, and $3.5 \mu \mathrm{L}$ PCR-grade water in a total $10 \mu \mathrm{L}$ reaction volume. Initial holding and activation of DNA polymerase was at $50{ }^{\circ} \mathrm{C}$ for 2 minutes. RT-PCR was performed for 40 cycles of $95^{\circ} \mathrm{C}$ for 20 seconds and $60^{\circ} \mathrm{C}$ for 40 seconds. A post-PCR melt curve was performed between $60{ }^{\circ} \mathrm{C}$ to $95{ }^{\circ} \mathrm{C}$ with $0.3{ }^{\circ} \mathrm{C}$ temperature increments. Limit-of-detection assays, using serial dilutions $(100 \mathrm{ng} / \mu \mathrm{L}$ to $0.00001 \mathrm{ng} / \mu \mathrm{L})$ of DNA from $N$. gonorrhoeae reference strains WHO F, P, G, K, and N, were used to ascertain the sensitivity of each primer pair. DNA from 40 non-N. gonorrhoeae and non-Neisseria species was also used to test the specificity of each primer pair.

\subsection{Real Time PCR and Hydrogel Methods}

To compare hydrogel and RT-PCR methods, DNA was amplified using three N. gonorrhoeae diagnostic primer pairs $(3,17-1$, and 21-5) and a SYBR Select master mix. For the RT-PCR control method, each reaction contained $2 \mu \mathrm{L}$ DNA $(50,70$, or $100 \mathrm{ng} / \mu \mathrm{L}), 1.5 \mu \mathrm{L}$ of each primer $(10 \mu \mathrm{M})$ and $5 \mu \mathrm{L} 2 \times$ SYBR-Green master mix in a total $10 \mu \mathrm{L}$ reaction volume. For the hydrogel method, each reaction contained $1 \mu \mathrm{L}$ DNA $(50,70$, or $100 \mathrm{ng} / \mu \mathrm{L}), 0.38 \mu \mathrm{L}$ of each primer $(10 \mu \mathrm{M})$, and $8.24 \mu \mathrm{L}$ PCR-grade water. $2 \times$ SYBR-Green and primers were pre-mixed with the hydrogel. DNA and water were added to the hydrogel immediately before the start of the RT-PCR assay. Initial holding and activation of DNA polymerase was at $50^{\circ} \mathrm{C}$ for 2 minutes. RT-PCR was then performed for 30 cycles of $95^{\circ} \mathrm{C}$ for 20 seconds and $60{ }^{\circ} \mathrm{C}$ for 40 seconds. A post PCR melt curve was performed between $60^{\circ} \mathrm{C}$ to $95{ }^{\circ} \mathrm{C}$ with $0.3{ }^{\circ} \mathrm{C}$ temperature increments.

Various RT-PCR conditions were tested to optimize the hydrogel method. The final assay conditions included: $30 \mathrm{PCR}$ cycles, $60{ }^{\circ} \mathrm{C}$ annealing temperature, $60-95{ }^{\circ} \mathrm{C}$ melt curve temperature range, $0.3^{\circ} \mathrm{C}$ image taking temperature increments, and $2 \times$ SYBR-Green concentration.

\section{Conclusions}

The hydrogel method coupled with the primers discussed in this work can meet the ideal rapid test (ASSURED) criteria established by WHO for STI diagnosis tests; Affordable, Sensitive, Specific, User-friendly, Robust and Rapid, Equipment-free, and Deliverable to end users [21]. Although the hydrogel system was evaluated using pure cultures of $N$. gonorrhoeae, with further optimization the hydrogel diagnostic method with these primers can be used as a POCT for the diagnosis of gonococci from clinical specimens enabling rapid, reliable, and efficient diagnosis of N. gonorrhoeae. Furthermore, multiplex primer pairs can be integrated into the hydrogel platform enabling simultaneous diagnosis of N. gonorrhoeae and characterization of its AMR profile to different antimicrobials.

Supplementary Materials: The following are available online at http:/ / www.mdpi.com/2079-6382/7/3/0070/s1, Table S1: Primer sequences used in this study for detection of $N$. gonorrhoeae, their respective targets and copy numbers present in the N. gonorrhoeae genome.

Author Contributions: S.R.P. performed laboratory experiments, validation and formal analysis of data, design methodology and drafted the original manuscript. A.T. designed and validated the primers. N.H.K. performed preliminary laboratory experiments and data analysis, designed methodology. R.P.P. was involved in preliminary protocol design and funding acquisition. S.S., P.S. and J.P.A. developed and supplied the hydrogels. I.M. supplied the N. gonorrhoeae DNA. A.K. designed the primers and reviewed the manuscript. J.R.D. conceptualized the project, provided supervision and project administration, acquired funding, reviewed and edited drafts of the manuscript and was responsible for the final draft. All authors reviewed the final draft of the manuscript.

Funding: This research was funded by Grand Challenges Canada, grant S5-0398-01; Natural Sciences and Engineering Research Council (NSERC) Engage, grant 416467; Canadian Institutes of Health Research (CIHR), grant 418246; and the University of Saskatchewan. S.R.P. was supported by a University of Saskatchewan, College of Medicine Scholarship.

Acknowledgments: We thank Aquila Diagnostic Systems Inc., Edmonton AB, Canada for supplying the hydrogels. 
Conflicts of Interest: S.S., P.S. and J.P.A. are employees of, and hold shares in, Aquila Diagnostic Systems Inc. The authors declare no other conflicts of interest.

\section{References}

1. Newman, L.; Rowley, J.; Vander Hoorn, S.; Wijesooriya, N.S.; Unemo, M.; Low, N.; Stevens, G.; Gottlieb, S.; Kiarie, J.; Temmerman, M. Global estimates of the prevalence and incidence of four curable sexually transmitted infections in 2012 based on systematic review and global reporting. PLoS ONE 2015, 10, e0143304. [CrossRef] [PubMed]

2. Walker, C.K.; Sweet, R.L. Gonorrhea infection in women: prevalence, effects, screening and management. Int. J. Wom. Hlth. 2011, 3, 197-206.

3. Bignell, C.; FitzGerald, M. UK National guideline for the management of gonorrhoea in adults, 2011. Int. J. STD AIDS 2011, 22, 541-547. [CrossRef] [PubMed]

4. Dillon, J.R.; Parti, R.P.; Thakur, S.D. Antibiotic resistance in Neisseria gonorrhoeae: will infections be untreatable in the future? Culture 2015, 35, 1-8.

5. Unemo, M.; Nicholas, R.A. Emergence of multidrug-resistant, extensively drug-resistant and untreatable gonorrhea. Future Microbiol. 2012, 7, 1401-1422. [CrossRef] [PubMed]

6. Global action plan to control the spread and impact of antimicrobial resistance in Neisseria gonorrhoeae. Available online: http:/ / www.who.int/reproductivehealth/publications/rtis/9789241503501/en/ (accessed on 15 January 2018).

7. Tabrizi, S.N.; Unemo, M.; Limnios, A.E.; Hogan, T.R.; Hjelmevoll, S.O.; Garland, S.M.; Tapsall, J. Evaluation of six commercial nucleic acid amplification tests for detection of Neisseria gonorrhoeae and other neisseria species. J. Clin. Microbiol. 2011, 49, 3610-3615. [CrossRef] [PubMed]

8. Pope, C.F.; Hay, P.; Alexander, S.; Capaldi, K.; Dave, J.; Sadiq, S.T.; Ison, C.A.; Planche, T. Positive P redictive value of the becton dickinson VIPER system and the ProbeTec GC Qx assay, in extracted mode, for detection of Neisseria gonorrhoeae. Sex. Transm. Infect. 2010, 86, 465-469. [CrossRef] [PubMed]

9. Moncada, J.; Clark, C.B.; Holden, J.; Hook III, E.W.; Gaydos, C.A.; Schachter, J. Stability studies on dry swabs and wet mailed swabs for detection of Chlamydia trachomatis and Neisseria gonorrhoeae in aptima assays. J. Clin. Microbiol. 2017, 55, 971-977. [CrossRef] [PubMed]

10. Graham, R.M.A.; Doyle, C.J.; Jennison, A.V. Epidemiological typing of Neisseria gonorrhoeae and detection of markers associated with antimicrobial resistance directly from urine samples using next generation sequencing. Sex. Transm. Infect. 2017, 93, 65-67. [CrossRef] [PubMed]

11. Badman, S.G.; Vallely, L.M.; Toliman, P.; Kariwiga, G.; Lote, B.; Pomat, W.; Holmer, C.; Guy, R.; Luchters, S.; Morgan, C. A novel point-of-care testing strategy for sexually transmitted infections among pregnant women in high-burden settings: results of a feasibility study in Papua New Guinea. BMC Infect. Dis. 2016, 16, 250. [CrossRef] [PubMed]

12. Makoka, M.H.; Komolafe, O.O. Evaluation of syndromic management of sexually transmitted infections in Blantyre, Malawi. Malawi Med. J. 2004, 16, 9-13. [PubMed]

13. Guy, R.J.; Causer, L.M.; Klausner, J.F.; Unemo, M.; Toskin, I.; Azzini, A.M.; Peeling, R.W. Performance and operational characteristics of point-of-care tests for the diagnosis of urogenital gonococcal infections. Sex Transm. Infect. 2017, 93, S16-S21. [CrossRef] [PubMed]

14. Wynn, A.; Ramogola-Masire, D.; Gaolebale, P.; Moshashane, N.; Sickboy, O.; Duque, S.; Williams, E.; Doherty, K.; Klausner, J.D.; Morroni, C. Prevalence and treatment outcomes of routine Chlamydia trachomatis, Neisseria gonorrhoeae and Trichomonas vaginalis testing during antenatal care, Gaborone, Botswana. Sex. Transm. Infect. 2018, 94, 230-235. [PubMed]

15. Taylor-Robinson, D.; Pallecaros, A.; Horner, P. Diagnosis of some genital-tract infections: part i. an historical perspective. Int. J. STD AIDS 2017, 28, 1143-1149. [CrossRef] [PubMed]

16. Gift, T.L.; Pate, M.S.; Hook 3rd, E.W.; Kassler, W.J. The rapid test paradox: when fewer cases detected lead to more cases treated: A decision analysis of tests for Chlamydia trachomatis. Sex. Trasm. Dis. 1999, 26, 232-240. [CrossRef]

17. Watchirs Smith, L.A.; Hillman, R.; Ward, J.; Whiley, D.M.; Causer, L.; Skov, S.; Donovan, B.; Kaldor, J.; Guy, R. Point-of-care tests for the diagnosis of Neisseria gonorrhoeae infection: a systematic review of operational and performance characteristics. Sex. Transm. Infect. 2013, 89, 320-326. [CrossRef] [PubMed] 
18. Otero-Guerra, L.; Fernandez-Blazquez, A.; Vazquez, F. Rapid diagnosis of sexually trasmitted infections. Enferm. Infecc. Microbiol. Clin. 2017, 35, 444-450. [CrossRef] [PubMed]

19. Aptima Combo 2®Assay. Available online: https://www.hologic.com/sites/default/files/package-insert/ 502487-IFU-PI_001_01.pdf. (accessed on 18 January 2018).

20. Harding-Esch, E.M.; Nori, A.V.; Hegazi, A.; Pond, M.J.; Okolo, O.; Nardone, A.; Lowndes, C.M.; Hay, P.; Sadiq, S.T. Impact of deploying multiple point-of-care tests with a 'sample first' approach on a sexual health clinical care pathway. a service evaluation. Sex. Transm. Infect. 2017, 93, 424-429. [CrossRef] [PubMed]

21. Pai, M.; Ghiasi, M.; Pai, N.P. Point-of-care diagnostics testing in global health: what is the point? Microbe 2015, 10, 103-107. [CrossRef]

22. Peeling, R.W.; Holmes, K.K.; Mabey, D.; Ronald, A. Rapid tests for sexually transmitted infections (stis): The way forward. Sex. Transm. Infect. 2006, 82, v1-v6. [CrossRef] [PubMed]

23. Manage, D.P.; Lauzon, J.; Atrazhev, A.; Morrissey, Y.C.; Edwards, A.L.; Stickel, A.J.; Crabtree, H.J.; Pabbaraju, K.; Zahariadis, G.; Yanow, S.K. A miniaturized and integrated gel post pllatform for multiparameter pcr detection of herpes simplex viruses from raw genital swabs. Lab Chip 2012, 12, 1664-1671. [CrossRef] [PubMed]

24. Taylor, B.J.; Howell, A.; Martin, K.A.; Manage, D.P.; Gordy, W.; Campbell, S.D.; Lam, S.; Jin, A.; Polley, S.D.; Samuel, R.A. A lab-on-chip for malaria diagnosis and surveillance. Malar. J. 2014, 13, 179. [CrossRef] [PubMed]

25. Manage, D.P.; Morrissey, Y.C.; Stickel, A.J.; Lauzon, J.; Atrazhev, A.; Acker, J.P.; Pilarski, L.M. On-chip PCR amplification of genomic and viral templates in unprocessed whole blood. Microfluid Nanofluidics 2011, 10, 697-702. [CrossRef]

26. Vidovic, S.; Caron, C.; Taheri, A.; Thakur, S.D.; Read, T.D.; Kusalik, A.; Dillon, J.A. Using crude whole-genome assemblies of Neisseria gonorrhoeae as a platform for strain analysis: clonal spread of gonorrhea infection in saskatchewan, Canada. J. Clin. Microbiol. 2014, 52, 3772-3776. [CrossRef] [PubMed]

27. Vidovic, S.; Horsman, G.B.; Liao, M.; Dillon, J.R. Influence of conserved and hypervariable genetic markers on genotyping circulating strains of Neisseria gonorrhoeae. PLoS ONE 2011, 6, e28259. [CrossRef] [PubMed]

28. Liao, M.; Helgeson, S.; Gu, W.M.; Yang, Y.; Jolly, A.M.; Dillon, J.R. Comparison of Neisseria gonorrhoeae multiantigen sequence typing and porB sequence analysis for identification of clusters of N. gonorrhoeae isolates. J. Clin. Microbiol. 2009, 47, 489-491. [CrossRef] [PubMed]

29. Unemo, M.; Fasth, O.; Fredlund, H.; Limnios, A.; Tapsall, J. Phenotypic and genetic characterization of the 2008 WHO Neisseria gonorrhoeae reference strain panel intended for global quality assurance and quality control of gonococcal antimicrobial resistance surveillance for public health purposes. J. Antimicrob. Chemother. 2008, 63, 1142-1151. [CrossRef] [PubMed]

30. Gaydos, C.A.; Van Der Pol, B.; Jett-Goheen, M.; Barnes, M.; Quinn, N.; Clark, C.; Daniel, G.E.; Dixon, P.B.; Hook III, E.W. The CT/NG study group. performance of the cepehid CT/NG Xpert rapid pcr test for detection of Chlamydia trachomatis and Neisseria gonorrhoeae. J. Clin. Microbiol. 2013, 51, 1666-1672. [CrossRef] [PubMed]

31. Tabrizi, S.N.; Unemo, M.; Golparian, D.; Twin, J.; Limnios, A.E.; Lahra, M.; Guy, R. Analytical evaluation of GeneXpert CT/NG, the first genetic point-of-care assay for simultaneous detection of Neisseria gonorrhoeae and Chlamydia trachomatis. J. Clin. Microbiol. 2013, 51, 1945-1947. [CrossRef] [PubMed]

32. Speers, D.J.; Chua, I.J.; Manuel, J.; Marshall, L. Detection of Neisseria gonorrhoeae and Chlamydia trachomatis from pooled rectal, pharyngeal and urine spciemsn in men who have sex with men. Sex. Transm. Infect. 2018, 94, 293-297. [CrossRef] [PubMed]

33. Peuchant, O.; de Diego, S.; Le Roy, C.; Frantz-Blancpain, S.; Hocke, C.; Bebear, C.; de Barbeyrac, B. Comparison of Three real-time PCR assays for the detection of chlamydia trachomatis and neisseria gonorrhoeae in young pregnant women. Diagn. Microbiol. Infect. Dis. 2015, 83, 335-337. [CrossRef] [PubMed] 
34. Recommendations for the Laboratory-Based Detection of Chlamydia Trachomatis and Neisseria Gonorrhoeae-2014. Available online: https://www.cdc.gov/mmwr/preview/mmwrhtml/rr6302a1.htm\# Tab3 (accessed on 14 December 2017).

35. Han, Y.; Yin, Y.-P.; Shi, M.-Q.; Zheng, B.-J.; Zhong, M.-Y.; Hiang, N.; Chen, S.-C.; Chen, X.-S. Evaluation of abbott real-time CT/NG assay for detection of chlamydia trachomatis and Neisseria gonorrhoeae in cervical swabs from female sex workers in China. PLOS ONE 2014, 9, e89658.

36. Ye, J.; Coulouris, G.; Zaretskaya, I.; Cutcutache, I.; Rozen, S.; Madden, T.L. Primer-BLAST: A tool to design target-specific primers for polymerase chain reaction. BMC Bioinform. 2012, 13, 134. [CrossRef] [PubMed]

(C) 2018 by the authors. Licensee MDPI, Basel, Switzerland. This article is an open access article distributed under the terms and conditions of the Creative Commons Attribution (CC BY) license (http://creativecommons.org/licenses/by/4.0/). 